\title{
Geyik elması'nın (Eriolobus trilobatus) doğal yayılış alanları, bazı morfolojik, ekolojik ve etnobotanik özellikleri: Antalya ili örneği
}

\section{Natural distribution areas of crab apple (Eriolobus trilobatus), some morphological, ecological and ethnobotanical properties: The case of Antalya province}

\author{
Nurtaç ÇINAR ${ }^{10}$, R. Süleyman GÖKTÜRK² \\ ${ }^{1}$ Batı Akdeniz Tarımsal Araştırma Enstitüsü, Antalya, Türkiye \\ ${ }^{2}$ Akdeniz Üniversitesi, Fen Fakültesi, Biyoloji Bölümü, Antalya, Türkiye \\ Sorumlu yazar (Corresponding author): N. Çınar, e-posta (e-mail): nurtac.cinar@ tarimorman.gov.tr \\ Yazar(lar) e-posta (Author e-mail): gokturk@akdeniz.edu.tr
}

\section{MAKALE BİLGİİ}

Alınış tarihi 10 Temmuz 2019

Düzeltilme tarihi 06 Eylül 2019

Kabul tarihi 09 Eylül 2019

\section{Anahtar Kelimeler:}

Eriolobus trilobatus

At elmas1

Gömbe

İklimsel özellikler

Toprak analizleri

\begin{abstract}
ÖZ
Yabani bir meyve olan Geyik/ At elması (Eriolobus trilobatus (Labill. ex Poiret) M. Roem.), sınırlı yayılışa sahip, kuraklığa dayanıklı, peyzaja uygun, aromalı meyvelere sahip odunsu bir türdür. Bu çalışmada Antalya ilinde doğal olarak bulunan geyik elması ağaçlarının yayılıș alanları, bazı lokasyon ve ağaç özellikleri (iklimsel özellikler, toprak özellikleri, floristik yapı, genel fenolojik gelişim, ağaç boy ve çap ölçümleri, taç şekli, biyotik ve abiyotik faktör etkileri) ve etnobotanik kullanımı araștırılmıștır. Türün Antalya'da nadir olarak bulunduğu, 710-1400 metre yükseltilerdeki çam ormanları ve meşelikler içinde nötr, kireçli, tuzsuz ve kum oranı yüksek topraklarda yayılış gösterdiği görülmüştür. Yaprak ve meyvelerinin kalp hastalıkları, şeker, astım, gastrit gibi rahatsızlıklara karşı tüketilmekte olduğu, ancak günümüzde eski önemini kaybettiği bildirilmiştir. Ekokültürel önemi bulunan geyik elması ağaçlarının korunması, doğal popülasyonlarının artırılması ve farklı alanlarda değerlendirilmesi gerektiği düşünülmektedir.
\end{abstract}

\section{ARTICLE INFO}

Received 10 July 2019

Received in revised form 06 September 2019 Accepted 09 September 2019

\section{Keywords:}

Eriolobus trilobatus

Crab apple

Gömbe

Climatic characteristics

Soil analysis

\begin{abstract}
A wild fruit, crab apple (Eriolobus trilobatus (Labill. ex Poiret) M. Roem.), is a woody species that is limited distribution, resistant to drought, suitable for landscaping and has fruit flavored. In this study, the distribution areas of crab apple trees naturally found in Antalya province, some location and tree characteristics (climatic characteristics, soil characteristics, floristic structure, general phenological development, tree height and diameter measurements, crown shape, biotic and abiotic factor effects) and ethnobotanical use was investigated. It is observed that the species is rarely found in Antalya and it is distributed in neutral, chalky, salt-free and high-sand soils in pine and oak forests, at 710-1400 $\mathrm{m}$ altitude. It has been reported that the leaves and fruits are consumed against diseases such as heart diseases, sugar, asthma and gastritis, but they have lost their old importance today. It is thought that conservation of crab apple trees, which have ecocultural importance, increase their natural populations and be evaluated in different areas.
\end{abstract}

\section{Giriș}

Sahip olduğumuz bitkisel zenginliğin günümüzden geleceğe aktarılması, bitkisel çeşitliliğimizin tanınması, korunması ve saklanması ile mümkün olacaktır. Özellikle nadir bulunan, insanlar tarafindan tahrip edilmeye müsait özellikler taşıyan ve doğada kendiliğinden çoğalma oranı çok düşük olan türlerin araştırılması ve korunması önem taşımaktadır. Türkçe isimlendirme sisteminde 'at elması' olarak geçen ve 'geyik elması' ya da 'geyicek' olarak bilinen Eriolobus trilobatus türü de ilginç ve öncelikli koruma gerektiren nadir türlerden biridir
(Y1lmaz 2008; Aslan 2012; Yılmaz ve Yüksel 2014). Geyik elmas1, mimari özgünlüğü yansıtan, yaban yaşamında, peyzaj düzenlemelerinde ve erozyon kontrol çalışmalarında kullanım potansiyeli bulunan önemli ağaçlardan biridir (Gültekin 2011). Türün İngilizcesi 'erect crab' ya da 'crabapple' olarak geçmekte, Yunanistan'da 'bragania', 'Lübnan yabani elması' yada 'üç loblu elma ağacı' olarak da isimlendirilmektedir (Wood 2015). 
Tek türle temsil edilen Eriolobus (Ser) M. Roem. cinsi relikt olarak tanımlanmakta ve Malus türlerinin en ilkellerinden biri olan M. doumeri A. Chev. (M. laoensis)'den bağımsız olarak geliştiği (Ponomarenko 1989), Malus cinsine dâhil edilmesi tartışmalı olsa da, bu cins içinde yer alan türlerle yakın ilişkili olduğu belirtilmektedir (MingHao 2001). Bazı kaynaklarda Malus trilobata (Labil ex. Poir.) C. K. Schneid. şeklinde bir Malus türü olarak da belirtilen Eriolobus, diğer bazı sınıflandırmalarda Malus cinsi içinde Cloromeles (Decne.) Rahder ile Docyniopsis C. K. Schneid seksiyonları arasında yer alan ayrı bir seksiyon olarak, bazı kaynaklarda ise Eriolobus şeklinde kendi cinsini oluşturur şekilde yer almaktadır (Davis 1972; Robertson ve ark. 1991; Rohrer ve ark. 1994; Robinson 2001; Ganeva ve Uzunova 2010; Papamattheakis 2013).

Eriolobus trilobatus dünyada Doğu Akdeniz kıyılarında; Kuzeydoğu Yunanistan, Güneydoğu Bulgaristan, Batı ve Güney Anadolu, Suriye, Filistin, Lübnan ve Kuzey İsrail'de doğal olarak bulunmaktadır (Davis 1972; Korakis 2006; Gültekin 2011; Petrova 2015). Ülkemizdeki yayılışının Akdeniz, Ege ve İç Anadolu Bölgeleri'nde 700-1500 metreler arasında olduğu, Antalya, Balıkesir, Çanakkale, Denizli, Gaziantep, Hatay, Isparta, İzmir, Kahramanmaraş, Karaman, Konya, Kütahya, Manisa, Mersin, Muğla, Osmaniye ve Uşak illerinde bulunduğu ve yayılış yoğunluğunun tam olarak bilinmediği vurgulanmaktadır (Browicz ve Karaca 1993; Tuzlac1 2002; Gültekin 2011; Yılmaz ve Ok 2012; Orman Genel Müdürlüğü 2013; Yılmaz ve Yüksel 2014; Petrova 2015; Y1lmaz ve ark. 2019).

Türün diğer Rosaceae familyası üyelerinden ayrımı geç çiçek açması (mayıs-haziran) ve beyaz çiçeklerinin büyüklüğü (çap1 $4 \mathrm{~cm}$ ) ile sağlanmaktadır (Korakis 2006). Rosaceae familyası içinde cins teşhis anahtarı Eriolobus cinsini yaprakların basit ve derince loblu olması, çiçeklerinin petalli olması ve epikaliks bulundurmamas1, ovaryumun alt durumlu olması ve pome tipi meyvesi, çiçeklerin basit korimboz yada şemsiye halinde bulunması, dikensiz olması, sepallerin kalıcı olması gibi özellikleri ile diğer cinslerden ayırmaktadır. Malus cinsi ile ayrım noktası ise yapraklarının lob içermesi olarak tanımlanmaktadır (Davis 1972). Türün yaprak biçimi ve boyutlarına dayanılarak 3 varyetesinin (var. oxylobus Kotschy, var. rumelicus Dingler, var. sorgerae Browicz) betimlendiği bildirilmiştir (Browicz ve Karaca 1993). Ancak çok küçük (10$30 \mathrm{~mm}$ ) yaprakları ve alt kısmında belirgin tüylerinin bulunması, haziran ayında çiçeklenmesi, yayılış yükseltisinin 1200 m olması ve sadece tip örneği olarak tanımlandığı Antalya Gömbe'de bulunması ile karakterize edilen sorgerae varyetesi bir süre korunsa da günümüzde hepsi geçerliliğini yitirmiştir (Aslan 2012).

Literatür bilgileri ülkemizde tür üzerine yapılan az sayıda çalışma olduğunu, nadir bulunan bir orman ağacı olduğundan orman araştırmaları kapsamında öncelikli olmadığını ve ilimizde iki varyete ile temsil edilmiş bulunan türe ait bir çalışmanın bulunmadığını göstermiştir. $\mathrm{Az}$ bilinen türün tanınmasına ve ekokültürel değerini yeniden kazanmasına olanak sağlayacağını düşündüğümüz çalışmamızda türün Antalya ilindeki doğal yayılış alanları, lokasyon özellikleri, ağaçlara ait ölçüm ve gözlemler ve etnobotanik kullanımına ilişkin bilgiler derlenmiştir.

\section{Materyal ve Yöntem}

Çalışmanın materyalini Antalya sınırları içinde doğal yayılış gösteren geyik elması (E. trilobatus) türüne ait ağaçlar oluşturmuş ve araştırma 2014-2017 yılları arasında yürütülmüştür.

\section{1. İklimsel özelliklerin belirlenmesi}

Geyik elması ağaçlarının bulunduğu lokasyonlara ait iklimsel özellikler Devlet Meteoroloji İşleri Genel Müdürlüğü bünyesinde Çalaman ve Çalaman (2004) tarafindan uzun yıllar (1980-2000 yılları arasındaki) ortalamaları esas alınarak oluşturulan harita verilerine göre yıllık ve aylık ortalama ölçümler şeklinde hazırlanmıştır.

\subsection{Toprak özelliklerinin belirlenmesi}

Toprak örnekleri 2014 yılı Mayıs ayında ağaçlara ait taç izdüşümlerinin 3 ayrı noktasından alınarak paçal yapılmış ve analiz edilmiştir. Toprak örneklerinde $\mathrm{pH}, \mathrm{CaCO}_{3}$ içeriği, elektriksel iletkenlik (EC), bünye (kum, kil, mil içeriği), organik madde, alınabilir fosfor (P), değişebilir potasyum (K), kalsiyum (Ca) ve magnezyum $(\mathrm{Mg})$ değerleri belirlenmiştir.

\subsection{Bitki florasının belirlenmesi}

Farklı dönemlerde ağaçlar etrafında bulunan otsu ve odunsu bitkiler incelenmiş, teşhis edilerek listelenmiştir. Teşhiste Türkiye Florası kitap seti (Davis ve ark. 1972), bitkilerin Türkçe isimlendirilmesinde ise Türkiye Bitkileri Listesi-Damarlı Bitkiler (Güner ve ark. 2012) kitabı kullanılmıştır.

\subsection{Genel fenolojik gelişimin belirlenmesi}

Ağaçlar farklı dönemlerde incelenerek çiçeklenme tarihleri, meyve olgunluk durumları ve meyve dönemi yaprak renkleri gözlemlenmiştir.

\section{5. Ăgaç özelliklerinin belirlenmesi}

Ağaçların büyüme şekli gözlemlenmiş, gövde çevresi şeritmetre ile yerden yaklaşık 1.5 metre yukarıdan ölçülerek $\mathrm{cm}$ olarak belirlenmiştir. Ağaç boyları ağacın bütününü içerecek şekilde boyu bilinen bir nesne ile fotoğraflanıp oranlanmak suretiyle metre olarak belirlenmiş ve bireylerin ağaç ve ağaççık olma durumları değerlendirilmiştir. Boyu 3-6 metre aralığında bulunanlar ağaççık, 6 metre üstü olanlar ağaç olarak tanımlanmıştır (Ellison 2002). Ayrıca ağaçlara etki eden biyotik ve abiyotik etmenler gözlemlenmiştir.

\subsection{Etnobotanik özelliklerinin belirlenmesi}

Ağaçlar etrafında, kahvehane, bakkal ve ev ziyaretlerinde yöre halkı ile anketler yapılmıştır. Katılımcılarla ilgili yaş, eğitim durumu, ikamet yeri, bitki kullanımının kimden öğrenildiği gibi bilgiler alınırken, bitki ile ilgili bitkinin yöresel adları, kullanım amac1, kullanılan kısımları, tedavi edici özellikleri, nereden temin edildiği, hangi şekillerde değerlendirildiği ve muhafaza edildiği gibi bilgiler derlenmiştir (Satıl ve ark. 2008; Polat 2010; Sayılı ve ark. 2010).

\section{Bulgular}

Ağaçların orman vejetasyonunda 710-1400 metre yükseltide bulunduğu, çoğu lokasyonda bir/ iki yaşlı ağaç bulunurken, Akseki, Kaş, Kumluca ve Korkuteli'nde ağaç sayısının fazla (4-11 adet) olduğu ve genç bireylerin de yer aldığ görülmüştür. Çalışmamızda 8 ilçeye ait 16 farklı lokasyonda toplam 60 bireye rastlanmış, çiçeklenen sağlıklı birey sayısı 35 olarak belirlenmiştir. Ağaçlardan 4 tanesi özel mülk içinde olurken 
diğerleri orman kenarlarında bulunmuştur. Örnekleme yapılan lokasyonlara ait genel konum bilgileri Çizelge 1'de, Çăglarca lokasyonuna ait genel görünüm örneği Şekil 1'de verilmiştir. Ayrica Elmal1-Yılmazl, Termessos Millipark1, Kumluca-Altınyaka Mevkii ve Serik Yaylası'nda kuruyan ve kesilen ağaçların bulunduğu belirlenmiştir.

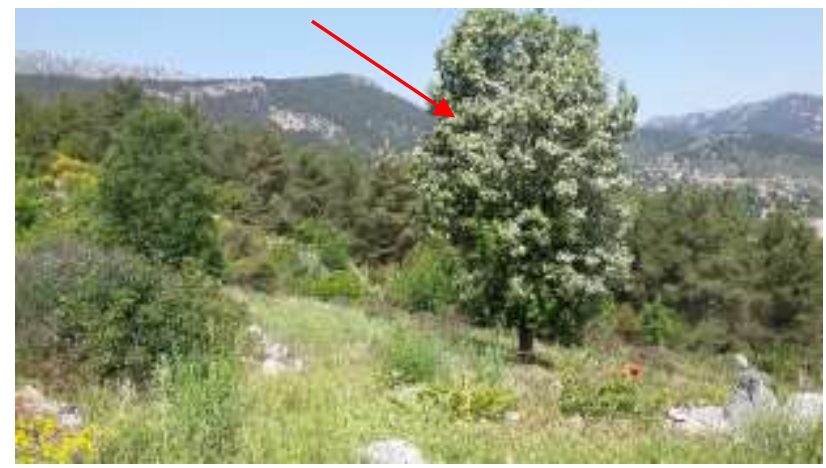

Şekil 1. Çiçek döneminde Çağlarca lokasyonunun genel görünümü.

Figure 1. General view of the Çağlarca location in the flower period.

\section{1. İklimsel özellikler}

Sıcaklık ve yağışa göre 5 karakteristik bölgeye ayrılan Antalya ilinde türün 3 bölgede (serin az yağışli, sıcak çok yağışl1, serin çok yağışlı) yayılış gösterdiği ve 2 bölgede (serin kurak, sıcak az yağışl1) ise bulunmadığ 1 görülmüştür. Sağlıklı bireylerin bulunduğu 12 lokasyona ait ortalama meteorolojik ölçümler Çizelge 2'de verilmiştir. Lokasyonlardaki yıllık ortalama sıcaklık değeri $5^{\circ} \mathrm{C}$ (Gömbe) ile $12^{\circ} \mathrm{C}$ (Çağlarca) arasında, yıllık ortalama toplam yağış miktarı $500 \mathrm{~kg} \mathrm{~m}^{-2}$ (Elmalı-Yörenler) ile $1200 \mathrm{~kg} \mathrm{~m}^{-2}$ (Akseki ve İbradı) arasında, y1llık ortalama yağışlı gün sayısı 70 gün (Kumluca-Gölcük) ile 93 gün (Akseki-Murtiçi) arasında değişmiştir.

Ağaç sayısının fazla olduğu Akseki-Cevizli ve Kaş-Gömbe lokasyonlarının en düşük sıcaklık değerine sahip lokasyonlar olduğu görülmüştür. Ortalama yağış miktarı incelendiğinde en düşük yağış $3 \mathrm{~kg} \mathrm{~m}^{-2}$ ile temmuz ve ağustos aylarında Çağlarca,
Kumluca (Üçoluk/Gölcük) ve Kaş-Gömbe lokasyonlarında olmuştur. İklimsel veriler, farklı varyete olarak tanımlı iken sinonim olan ve en genç ağaçların bulunduğu Gömbe lokasyonunun az yağış alan en soğuk lokasyon olduğunu göstermiştir. Mevcut konumu itibarı ile en yüksek rakımdaki, karasal iklime en yakın ve içinde bulunduğu bölgeye nazaran yağışın fazla olduğu, ayrıca 'Uçarsu' olarak bilinen dağdan çağlayarak akan su yollarının ortasında bulunan bu lokasyonun türün doğal çoğalımına olanak sağlayan mikroklima özelliğinde bir lokasyon olduğu görülmüştür.

\subsection{Toprak özellikleri}

Türün genel olarak nötr, kireçli, tuzsuz ve kum oranı yüksek topraklarda bulunduğu belirlenmiştir. Toprak örneklerinde $\mathrm{pH}$ 6.4-8.1, kireç $\left(\mathrm{CaCO}_{3}\right)$ içeriği \%0.9-21.3, elektriksel iletkenlik (EC) micromhos $\mathrm{cm}^{-1}\left(25^{\circ} \mathrm{C}\right) 90-449$, bünyede kum \%28-65, kil $\% 15-35.2$, mil \%20-50, organik madde \%0.7-9, alınabilir fosfor (P) 5-50 ppm, değişebilir potasyum (K) 188-950 ppm, kalsiyum (Ca) $164-950 \mathrm{ppm}$ ve magnezyum $(\mathrm{Mg})$ 169-688 ppm değerleri arasında değişmiştir (Çizelge 3).

\subsection{Floristik yapr}

Antalya ilinde türle birlikte genel olarak; Capparis spinosa L. (Kebere), Crataegus monogyna Jacq. subsp. monogyna (Yemişen), Cyclamen cilicicum Boiss.\& Heldr. (Şeytankabalağı), Juniperus excelsa M. Bieb. subsp. excelsa (Boz ardıç), Juniperus oxycedrus L. subsp. oxycedrus var. oxycedrus (Katran ardıc1), Phlomis grandiflora H. S. Thompson var. grandiflora (Bahargülü), Picnomon acarna (L) Cass. (Kılçıkdiken), Pinus nigra J. F. Arnold subsp. pallasiana (Lamb.) Holmboe var. pallasiana (Karaçam), Pyrus elaeagnifolia Pall. subsp. elaeagnifolia (Ahlat), Rosa canina L. (Kuşburnu), Rubus sanctus Schreb (Böğürtlen), Salvia tomentosa Mill. (Şalba), Smilax aspera L. (Gicırdikeni), Spartium junceum L. (Katırtırnağ1), Styrax officinalis L. (Ay1 findığı), Quercus cerris L. (Saçlı meşe), Quercus coccifera L. (Kermes meşesi) taksonlarının bulunduğu görülmüştür.

Çizelge 1. Antalya ilinde geyik elması ağaçlarına ait lokasyon bilgileri. Table 1. Location of erect crab trees in Antalya.

\begin{tabular}{lccc}
\hline İlçe & Lokasyon & Rakım $(\mathrm{m})$ & GPS Değerleri \\
\hline Akseki & Cevizli- Çatal & $1210-1252$ & $37^{\circ} 12.853 \mathrm{~K} / 31^{\circ} 44.248 \mathrm{D}$ \\
& Cevizli- Düdencik & $1033-1070$ & $37^{\circ} 11.114 \mathrm{~K} / 31^{\circ} 43.957 \mathrm{D}$ \\
İbradı & Murtiçi & $713-725$ & $37^{\circ} 04.571 \mathrm{~K} / 31^{\circ} 37.892 \mathrm{D}$ \\
Manavgat & İbradı & $764-766$ & $36^{\circ} 56.085 \mathrm{~K} / 31^{\circ} 44.996 \mathrm{D}$ \\
Merkez & Manavgat & 1055 & $37^{\circ} 03.722 \mathrm{~K} / 31^{\circ} 25.251 \mathrm{D}$ \\
Korkuteli & Çağlarca & 770 & $36^{\circ} 51.676 \mathrm{~K} / 30^{\circ} 28.304 \mathrm{D}$ \\
Kumluca & Güzle & $1240-1242$ & $36^{\circ} 56.228 \mathrm{~K} / 30^{\circ} 26.642 \mathrm{D}$ \\
& Üçoluk & $949-995$ & $36^{\circ} 41.700 \mathrm{~K} / 30^{\circ} 25.070 \mathrm{D}$ \\
Elmalı & Gölcük & $1164-1170$ & $36^{\circ} 40.534 \mathrm{~K} / 30^{\circ} 21.530 \mathrm{D}$ \\
& Yörenler & 1257 & $36^{\circ} 48.976 \mathrm{~K} / 29^{\circ} 50.382 \mathrm{D}$ \\
Kaş & Yapraklı & 1320 & $36^{\circ} 49.948 \mathrm{~K} / 29^{\circ} 47.907 \mathrm{D}$ \\
\hline
\end{tabular}


Çizelge 2. Uzun yıllar ortalamalarına göre lokasyonların ortalama meteorolojik ölçümleri (1980- 2000).

Table 2. Average meteorological measurements of locations according to long- term averages (1980- 2000).

\begin{tabular}{|c|c|c|c|c|c|c|c|c|c|c|c|c|}
\hline Yillık ortalama & $\mathrm{C} 1$ & $\mathrm{C} 2$ & $\mathrm{Mu}$ & $\dot{\mathrm{I}} \mathrm{b}$ & $\mathrm{Ma}$ & $\mathrm{Ça}$ & Gü & Üç & Gö & Yö & $\mathrm{Ya}$ & $\mathrm{Gm}$ \\
\hline Sicaklık $\left({ }^{\circ} \mathrm{C}\right)$ & 6 & 6 & 11 & 11 & 11 & 12 & 9 & 11 & 11 & 8 & 7 & 5 \\
\hline Yağış Miktarı $\left(\mathrm{kg} \mathrm{m}^{-2}\right)$ & 1200 & 1200 & 1200 & 1200 & 1100 & 900 & 600 & 900 & 800 & 500 & 600 & 700 \\
\hline Nispi Nem Oranı (\%) & 60 & 60 & 58 & 56 & 58 & 60 & 58 & 60 & 60 & 56 & 58 & 60 \\
\hline Güneşlenme Süresi (saat y1l ${ }^{-1}$ ) & 2920 & 2920 & 2880 & 2880 & 2880 & 3000 & 2960 & 3000 & 3000 & 3000 & 2960 & 2960 \\
\hline Yağışlı gün sayısı & 90 & 90 & 93 & 87 & 81 & 72 & 75 & 72 & 70 & 78 & 75 & 72 \\
\hline
\end{tabular}

C1: Cevizli- Çatal, C2: Cevizli- Düdencik, Mu: Murtiçi, İb: İbradı, Ma: Manavgat, Ça: Çağlarca, Gü: Güzle, Üç: Üçoluk, Gö: Gölcük, Yö: Yörenler, Ya: Yapraklı, Gm: Gömbe.

Çizelge 3. Eriolobus trilobatus türünün yayılış gösterdiği lokasyonların toprak analiz sonuçları.

Table 2. Soil analysis results of the locations of Eriolobus trilobatus species.

\begin{tabular}{|c|c|c|c|c|c|c|c|c|c|c|c|c|c|}
\hline No & Lokasyon & $\begin{array}{c}\mathrm{pH} \\
12.5^{-1} \\
\end{array}$ & $\begin{array}{c}\text { Kirec } \\
\%\end{array}$ & $\begin{array}{c}\text { EC micromhos } \mathrm{cm}^{-1} \\
\left(25^{\circ} \mathrm{C}\right)\end{array}$ & $\begin{array}{c}\text { Kum } \\
\%\end{array}$ & $\begin{array}{c}\text { Kil } \\
\%\end{array}$ & $\begin{array}{c}\text { Silt } \\
\% \\
\end{array}$ & Tekstür & $\begin{array}{c}\text { Organik } \\
\text { madde } \% \\
\end{array}$ & $\begin{array}{c}\mathrm{P} \\
\mathrm{ppm}\end{array}$ & $\begin{array}{c}\mathrm{K} \\
\mathrm{ppm}\end{array}$ & $\begin{array}{c}\mathrm{Ca} \\
\mathrm{ppm}\end{array}$ & $\begin{array}{l}\mathrm{Mg} \\
\mathrm{ppm}\end{array}$ \\
\hline 1 & Cevizli-Çatal & 7.1 & 0.9 & 238 & 44 & 21 & 34.8 & Killi Tin & 9.0 & 18 & 164 & 5782 & 245 \\
\hline 2 & Cevizli-Düden & 7.2 & 1.1 & 163 & 40 & 27 & 33.0 & Killi Tin & 5.5 & 6 & 188 & 4815 & 169 \\
\hline 3 & Murtiçi & 7.5 & 20.2 & 173 & 46 & 27 & 26.8 & Killi Tin & 4.2 & 9 & 259 & 7377 & 279 \\
\hline 4 & İbradı & 6.4 & 1.1 & 445 & 42 & 27 & 30.8 & Killi Tin & 6.9 & 33 & 348 & 5912 & 402 \\
\hline 5 & Manavgat & 7.8 & 2.0 & 100 & 31 & 40 & 29.0 & Siltli kil & 5.0 & 5 & 418 & 4300 & 135 \\
\hline 6 & Çağlarca & 8.0 & 2.6 & 142 & 65 & 15 & 20.0 & Kumlu Tin & 6.9 & 48 & 772 & 8631 & 688 \\
\hline 7 & Güzle & 7.7 & 19 & 116 & 28 & 35 & 36.8 & Siltli killi tın & 4.1 & 5 & 274 & 7281 & 203 \\
\hline 8 & Üçoluk & 7.0 & 1.1 & 106 & 44 & 27 & 28.8 & Killi Tin & 3.0 & 8 & 227 & 3474 & 208 \\
\hline 9 & Gölcuk & 8.1 & 11.9 & 98 & 54 & 23 & 22.8 & Tinlı & 1.24 & 18 & 234 & 5858 & 371 \\
\hline 10 & Yörenler & 7.2 & 4.5 & 375 & 50 & 27 & 22.8 & Killi Tin & 5.5 & 50 & 950 & 6601 & 410 \\
\hline 11 & Yapraklı & 8.0 & 12.1 & 90 & 54 & 19 & 26.8 & Tinlı & 0.7 & 8 & 216 & 6337 & 294 \\
\hline 12 & Gömbe & 7.5 & 21.3 & 449 & 34 & 16 & 50.0 & Siltli Tin & 3.4 & 6 & 234 & 4082 & 278 \\
\hline
\end{tabular}

\subsection{Genel fenolojik gelişim}

Türün Antalya ilindeki çiçeklenme başlangıcı genel olarak 10 Mayıs (Çağlarca Kasabası) ile 5 Haziran (Gömbe ve Cevizli Kasabaları) arasındaki 3 haftalı dönemde olmuş, çiçeklenmenin en geç olduğu Gömbe lokasyonunda çiçeklenme 15 Hazirana kadar devam etmiştir. En iyi meyve olgunlaşması güneş bakısının en iyi olduğu Murtiçi ve İbradı lokasyonlarında görülürken, yaprak rengi kızıllaşması en yüksek rakımda olan Gömbe Kasabası'nda en bariz olarak görülmüştür (Şekil 2).

\section{5. Ă̆aç özellikleri}

Ağaçların genel olarak oval formda olduğu, yaş ilerledikçe taç şeklinin yuvarlak şekil aldığı, eğimli arazi şartlarının ve rüzgâr yönünün taç yapısında deformasyona neden olduğu görülmüştür. Ağaç gövde çevresi 8-177 cm, gövde çapı 2.55$56.38 \mathrm{~cm}$, boy uzunluğu ise 2.6-13.86 m arasında değişmiştir. En uzun boy Üçoluk4 kodlu ağaçta, en kisa boy Gömbe6 kodlu fidanda olmuştur. Boy ölçümü yapılan 35 ağaçtan 28 tanesinin boyu 6 metreyi geçerek ağaç, 7 tanesi 6 metrenin altında kalarak ağaççı olarak yorumlanmıştır.

Ağaçlara etki eden biyotik etmenler; kesim, budama, sopa ile meyve çırpma ve yaprak/meyve toplama, gövdede ağaçkakan delikleri, yaprak ve çiçeklerde böcek gali ve doku ölümleri olmuştur. Cevizli Kasabası'nda ağaçlar üzerinde liken türlerinden; Pseudevernia furfuracea (L.) Zopf., Lecidella elaeochroma (Ach.) M. Choisy., Leconara sp. ve Hypogymnia sp., pamuk unlubiti olarak bilinen Phenacoccus solenopsis ve tür teşhisi yapılamayan Lepidopter larvaları görülmüştür. Meyvelerin Üçoluk, Güzle, Beydiğin lokasyonlarında keçiler tarafindan, İbradı lokasyonunda ise yaban domuzları tarafindan yendiği öğrenilmiştir. Ağaçlara etki eden abiyotik faktörler ise; yüksek gerilim hattı (Üçoluk Köyü-ağaçlarda kuruma) ve

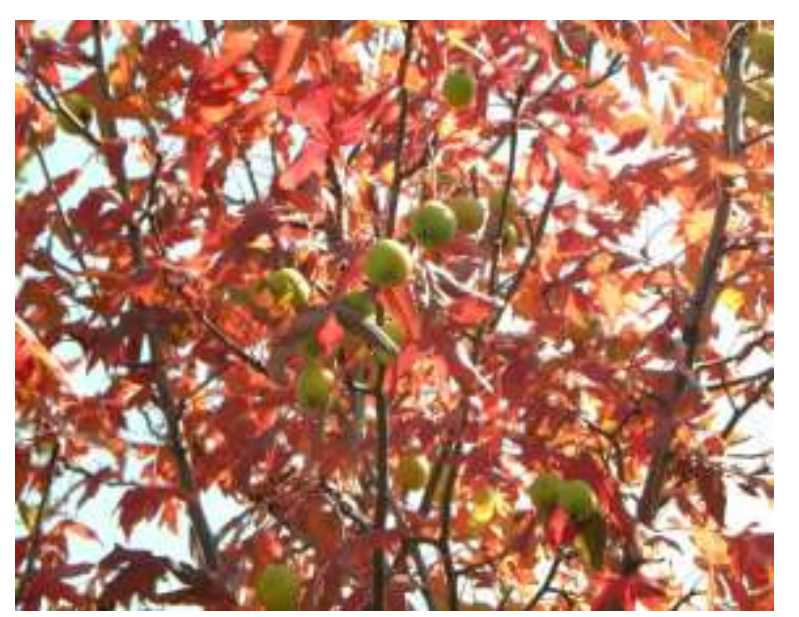

Şekil 2. Meyve döneminde Gömbe lokasyonu meyve ve yaprak örnekleri.

Figure 2. Fruit and leaf samples of Gömbe location in fruit period.

yaşlanma etkisiyle gövdede çatlaklar, kovuk ve kök sürgünü oluşumu olmuştur.

\subsection{Etnobotanik özellikler}

Ankete katılan katılımcıların (40 kiși) \%60'1 erkek, \%40’1 kadın olurken, yaş dağılımında \%16'sı 70-80 arası, \%30'u 60-70 aras1, \%30'u 50-60 aras1, \%19'u 40-50 aras1, \%5'i 30-40 arası olmuştur. Eğitim bakımından \%64'ünün ilkokul, $\% 15$ 'sinin ortaokul, \%11'inin lise, \%10'unun üniversite mezunu olduğu görülmüş, ayrıca katılımcıların \%88'inin lokasyon mevkiinde ikamet ettiği öğrenilmiştir. Anket çalışmasında elde edilen bulgular Çizelge 4'de verilmiştir. 
Çizelge 4. Etnobotanik anket bulguları.

Table 4. Ethnobotanical survey findings.

\begin{tabular}{|c|c|}
\hline Yöresel İsimleri & Geyik elması, Key elması, Geyik, Mor alıç, Geyik ağacı, Dağ elması, Keyik, Keel elma \\
\hline \multirow[t]{6}{*}{ Gida olarak kullanımı } & Taze meyve \\
\hline & Turşu, sirke (Elma delinerek sirkeye yatırılır elması turşu olarak, sirkesi şifa niyetine içilir) \\
\hline & Hoşaf (Tüm, ikiye bölünerek ya da meyvede çizikler oluşturularak kaynatılır) \\
\hline & Kak (Meyvelerin doğranarak kurutulmuş hali- yapılarak hoşaflık olarak muhafaza edilir) (İbradı- Akseki) \\
\hline & Reçel (Meyve ikiye bölünüp çekirdeği ile birlikte şurup içinde kaynatılarak yapılır) (İbradı) \\
\hline & Meyve kurusu (Köy bakkalında satılır- Kuzca Köyü- 2014 yılında kilosu 15 tl) \\
\hline \multirow[t]{9}{*}{ Tedavi amaçlı kullanımı } & Kalp hastalıkları; Meyve- yaprak karışık çay olarak demlenir, sabahları içilir (Çakırlar Köyü), \\
\hline & Sadece yaprak çayı aç karnına sabah bir bardak içilir (Cevizli Kasabası). \\
\hline & Diz bacak ağrısı: Yaprak çayı içilir. \\
\hline & Şeker hastalığı: Kurutulan yapraklar aç karnına çay olarak tüketilir. \\
\hline & Astım, nefes darlığı: Sabah aç karnına yaprak çayı içilir. \\
\hline & Meyve kurusu normal çay gibi demlenir, tokken içilir (Taşağıl Köyü). \\
\hline & Tansiyon dengesizliği: Meyve taze olarak yenir \\
\hline & Mide ağrısı, gastrit: Yaprak ıhlamur gibi kaynatılarak gün boyu içilir \\
\hline & Kabızlık: Meyveler çiğ olarak tüketilir \\
\hline \multirow[t]{3}{*}{ Nereden temin edildiği } & Doğadan toplama, komşu ikramı, pazardan alma \\
\hline & Çoğunlukla bu iș ile ilgilenen kişilere yapılan özel sipariș ile meyveler toplanır \\
\hline & Meyveleri nadiren taze olarak pazarlarda, kurutularak köy bakkalında satılır \\
\hline \multirow[t]{4}{*}{ Toplanma şekli } & Meyve ve yaprak beraber toplanır \\
\hline & Yapraklar sabah toplanıp, kurutulur \\
\hline & Meyveler genelde dökülünce toplanır \\
\hline & Yapraklar sabah erken ya da ikindi vakti güneş yokken toplanır (İbradı) \\
\hline \multirow[t]{4}{*}{ Muhafazası } & $\begin{array}{l}\text { Ağaçtan elle toplananlar (henüz yere düşüp bere almadan) su dolu bidonlar içinde oda sıcaklığında saklanır } \\
\text { (İbradı). }\end{array}$ \\
\hline & $\begin{array}{l}\text { Meyveler ilk soğuklarda (halk tabiri ile; kırağı yiyince) dökülür, çuval içine toplanır, olgunlaşması (halk } \\
\text { tabiri ile; ermesi beklenir, kış boyu yenir (Akseki Kuyucak Köyü ve İbradı) }\end{array}$ \\
\hline & $\begin{array}{l}\text { Tam olgunlaşmamış yeşilimsi meyveler saman içinde olgunlaştırılır ve kış boyu saklanarak tüketilir } \\
\text { (Kuyucak Köyü). }\end{array}$ \\
\hline & $\begin{array}{l}\text { Meyveler vaktinde toplanır, güneşte bekletilip buruşturulur, serin yerde şilte üzerinde serili olarak saklanır } \\
\text { (İbradı) }\end{array}$ \\
\hline
\end{tabular}

\section{Tartıșma ve Sonuc}

Genel bir değerlendirme ile Antalya ilinde geyik elması ağaçlarının günlük en yüksek toplam yağışı $130 \mathrm{~kg} \mathrm{~m}^{-2} \mathrm{den}$ daha az ve aylık ortalama sicaklığ $10{ }^{\circ} \mathrm{C}$ ve altında olan, $700 \mathrm{~m}$ yükselti üstündeki alanlarda yayılış gösterdiği belirlenmiştir. Türün ülkemizdeki yükselti kayıtlarının $125 \mathrm{~m}$ (Mersin) ile $1600 \mathrm{~m}$ (Kütahya) arasında olduğu, dünyadaki genel dağılımının ise $50 \mathrm{~m}$ (Bulgaristan) ile $1800 \mathrm{~m}$ (Lübnan) arasında değiştiği bilinmektedir (Browicz ve Karaca 1993; Zahreddine 2005; Y1lmaz ve Yüksel 2014). Antalya ilinde $713 \mathrm{~m}$ (Murtiçi-Akseki) ile $1390 \mathrm{~m}$ (Gömbe-Kaş) arasında bulunduğu görülmüştür. Genel yükseklik ortalaması Denizli, Muğla, İzmir, Manisa ve Balıkesir illerini kapsayan araştırma bölgesinde $698 \mathrm{~m}$ (Y1lmaz ve ark. 2019), Mersin ilinde $921 \mathrm{~m}$ (Yılmaz ve Yüksel 2014) olarak hesaplanırken, Antalya ilinde $1081 \mathrm{~m}$ olarak bulunmuş, türün ilimizdeki yükselti alt limitinin diğer illerden daha yüksek olduğu görülmüştür.

Lokasyonlara ait topraklar genel olarak nötr, kireçli, tuzsuz ve kum oranı yüksek topraklar olmuştur. Yılmaz ve Ok (2012) tarafindan da türün çoğunlukla kireçli topraklarda yayılış gösterdiği bildirilmiştir. Zahreddine ve ark. (2007) türün Lübnan'da (Ehden) yüksek pH, kalsiyum ve kireç ihtiva eden kumlu-tınlı topraklarda yayılış gösterdiğini bildirmişlerdir. Sonuçları bizim sonuçlarımızla kıyaslandığında $\mathrm{pH}$, EC ve organik madde miktarları değerlerimiz içinde yer alırken, kil, P, $\mathrm{K}, \mathrm{Ca}, \mathrm{Mg}$ oranları daha düşük bulunmuş, kireç oranı ise oldukça yüksek bulunmuştur. Toprak analizleri limit değerlere (Çokuysal ve Erbaş 2004) göre değerlendirildiğinde, kireç yönünden lokasyonlardan 5'i fakir, 2'si kireçli, 3'ü çok kireçli, 2'si çok fazla kireçli, organik madde bakımından 2'si fakir, 4'ü az, 6's1 yüksek, potasyum bakımından 2'si düşük, 6's1 yeterli, 1'i yüksek, 2'si çok yüksek, fosfor bakımından tüm lokasyonlar iyi, magnezyum bakımından 1'i orta, 7'si yüksek, 4'ü çok yüksek olarak yorumlanmıştır. Kalsiyum bakımından 1'i fazla, diğerleri çok fazla, elektriksel iletkenlik bakımından İbradı ve Gömbe hafif tuzlu, diğer lokasyonlar tuzsuz olmuştur. Türün genç ve sağlıklı ağaçlardan oluşan doğal popülasyonunun bulunduğu Gömbe lokasyonunda ise toprak özelliği nötre yakın hafif alkali, kireç oranı çok yüksek (\%21), elektriksel iletkenliği hafif tuzlu (449), mil oranı yüksek, organik madde miktarı az (3.4), potasyumu yeterli (234 ppm), kalsiyumu çok fazla (4082 ppm), magnezyumu ise yüksek (2789 ppm) bulunmuş, kireç ve tuz oranının diğer lokasyonlardan daha fazla olduğu görülmüştür.

Tür etrafindaki floristik yapı elemanları genel bir ifade ile çam (Pinus nigra J. F. Arnold subsp. pallasiana (Lamb.) Holmboe var. pallasiana-Karaçam ve Pinus brutia Ten. var. brutia-Kızılçam) ormanları ve meşelikler (Quercus cerris L. var. cerris-Saçlı meşe ve Quercus coccifera L.-Kermes meşesi) içinde farklı yabani meyveler ve otsu türler olmuştur. Kuzeydoğu Yunanistan'da (Korakis ve ark. 2016) ve Doğu Akdeniz Bölgesi'nde (Yılmaz ve Ok 2012) türün yayılış gösterdiği alanlarda beraberinde bulunduğu bildirilen odunsu bitkilerden bazıları ilimizde de görülürken, Arbutus andrachne L., Fraxinus ornus L. subsp. cilicica (Lingelsh.) Yalt., Acer monspessulanum L. subsp. monspessulanum gibi taksonlara Antalya lokasyonlarında rastlanmamıştır. Lübnan Ehden Bölgesi'nde de türün bulgularımızla uyumlu olarak Pinus brutia (varyete bilgisi verilmemiş) ormanları içinde Juniperus, Styrax, Sorbus, Cercis, ve Pistachia cinsleri ile birlikte yer aldığ bildirilmiş, ancak yine farklı olarak Fraxinus cinsi de yer almıştır (Zahreddine ve ark. 2007). Ege ve Güney Marmara Bölgesi için verilen kayıtlarda türün baskın olarak Balıkesir ve Denizli'de kızılçam, Muğla'da karaçam, kızılçam, ardıç ve laden (Cistus sp.), İzmir'de meşe, kızılçam ve ahlat türleriyle 
birlikte bulunduğu belirtilmiştir (Yılmaz ve ark. 2019). İlimizdeki floristik yapıda ise kızılçamın daha nadir olduğu görülmüştür. Çalışma bulgularımızdaki otsu ve çoğu çalımsı floristik yapı elemanı tür için ilk kez kaydedilmiştir.

Y1lmaz ve Ok (2012) tarafından Doğu Akdeniz Bölgesi için verilen gözlemlerle aynı olarak, ilimizde de ağaçların genç yaşta oval-piramidal yapıda olduğu, çoğu ağaç tek gövdeli iken, bazı ağaçlarda çatallı gövde yapısı bulunduğu görülmüştür. Doğu Akdeniz Bölgesi'nde en uzun birey $14 \mathrm{~m}$ (Kahramanmaraş-Kazma bağları) ve en kalın çaplı birey $75 \mathrm{~cm}$ (Kahramanmaraş-Önsen), Mersin'de en uzun boylu birey $16.8 \mathrm{~m}$, en kalın çaplı birey $81.8 \mathrm{~cm}$ olarak belirlenmiştir (Yılmaz ve Yüksel 2014). Ege ve Güney Marmara Bölgesi için en uzun birey $8.5 \mathrm{~m}$ ile İzmir'de, en kalın çaplı birey $18.7 \mathrm{~cm}$ ile Balıkesir'de bulunmuştur (Y1lmaz ve ark. 2019). İlimizde ise en uzun birey $13.86 \mathrm{~m}$ ile Üçoluk4 olurken, en kalın çaplı birey $56.38 \mathrm{~cm}$ ile Gölcük2 kodlu ağaç olmuştur. Yunanistan Evros Bölgesi'nde bulunan 5 lokasyondaki en iri ağaç boyutları $10 \mathrm{~m}$ boy ve $43 \mathrm{~cm}$ çap olarak belirlenmiştir (Korakis ve ark. 2016). Yunanistan ve Ege-Güney Marmara Bölgeleri’ndeki ağaçların ilimizdekilerden küçük olduğu görülürken, Mersin ve Kahramanmaraş illerindeki ağaçların ilimizdekilerden daha büyük olduğu görülmüştür.

Türe ait etnobotanik çalışmalar incelendiğinde Yılmaz ve Yüksel (2014) tarafindan Mersin yöresinde 'at elması' yada 'geyik elması' olarak bilindiği ve yaygın olarak sofralık meyve, turşu, sirke, kak ve çay şeklinde kullanıldığı belirtilmiştir. Türün Balıkesir'de 'gicik elma', 'gıccık elma' ve 'gece elması' olarak, Manisa'da "kıy elması" ve "keycek" olarak tanındığı ve sirke/ turşu yapımında kullanıldığı da bildirilmiştir (Yılmaz ve ark. 2019). İlimizde derlenen bilgilerde 'at elması' ve 'kıy elması' gibi söylemlere rastlanmamış, Akseki-İbradı Bölgesi'nde meyve bulunması durumunda değerlendirildiği, portakal/ elma gibi meyveler az bulunurken kıymetli olduğu,

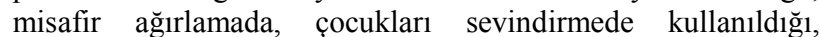
zamanla bu değerini yitirdiği öğrenilmiştir. Ülkemizde genel olarak türe ait ağaç sayısı ve meyve değerlendirme olanaklarının Doğu Akdeniz Bölgesi'nde yüksek olduğu, kolesterol, şeker, nefes darlığı ve tansiyona karşı kullanıldığı, Silifke ilçesinde anaçlık olarak da değerlendirildiği bilinmektedir (Yılmaz ve Yüksel 2014, Yılmaz ve Yüksel 2016). İlimizde anaçlık kullanıma rastlanmazken, tıbbi amaçla Mersin yöresine ilave olarak diz/ bacak ve mide ağrısına karşı kullanıldığı ve bağırsakları çalıştırarak zayıflattığı da öğrenilmiştir.

Ege ve Güney Marmara Bölgesi'nde yapılan çalışmada 151 ağaç belirlendiği, ağaç sayısının artırılması ve türün fonksiyonel kullanıma dâhil edilmesi gerektiği belirtilmiş (Yılmaz ve ark. 2019), Doğu Akdeniz Bölgesi'nde türe ait 2000'e yakın ağaç bulunmakta iken, türün tanıtımı ve korunması ile ilgili projelere ihtiyaç duyulduğu vurgulanmıştır (Yılmaz ve Ok 2012; Yılmaz ve Yüksel 2014; Yılmaz ve Yüksel 2016). İlimizdeki gözlemlerimizde ağaç sayısının 60 (5 adet fidan), sağlıklı birey sayısının 35 olarak belirlenmesi Batı Akdeniz Bölgesi'nde türün doğal popülasyonun korunması ve çoğaltılmasının daha da gerekli olduğunu göstermiştir. Türün dünyadaki genel dağılımı değerlendirildiğinde Doğu Akdeniz havzasında sınırlı ülkede ve sınırlı sayıda bulunduğu, ülkemizde geyik elması türü için doğal yayılıma uygun geniş geçit bölgelerinin (Toroslar vb.) ve iç bölgelerde soğuk ve nemli mikroklima alanlarının bulunması, ağaç sayısının en fazla olduğu ve bilimsel etkinlik bakımından öne çıan bir ülke olması gibi sebeplerle önemli bir konumda olduğu görülmektedir. Devam edecek çalışmalarla ülkemizdeki doğal yayılış alanlarında türe yönelik koruma, çoğaltım ve tanıtım faaliyetlerinin artırılması, ağaçlandırma/ erozyon kontrol çalışmalarında, meyvecilik, peyzaj ve tıbbi bitkiler sektörlerinde etkin şekilde değerlendirilmesi ve türün ekokültürümüzün bir parçası olarak benimsenmesi gerektiği düşünülmektedir.

\section{Teşekkür}

$\mathrm{Bu}$ çalışma Akdeniz Üniversitesi Bilimsel Araştırma Koordinasyon Birimi tarafindan 2014.03.0121.008 nolu proje ile desteklenen doktora tezinin bir bölümünden üretilmiştir.

\section{Kaynaklar}

Aslan S (2012) Eriolobus (Ser.) M. Roem. (Ed: Güner A, Aslan S, Ekim T, Vural M \& Babaç T), Türkiye Bitkileri (Damarlı Bitkiler). Nezahat Gökyiğit Botanik Bahçesi ve Flora Araştırmaları Derneği yayını, İstanbul, s. 798-801.

Browicz K, Karaca H (1993) Eriolobus triobatus (Pairet) Roemer in Turkey. The Karaca Arboretum Magazine II 2: 79-86.

Çalaman G, Çamalan İ (2004) Antalya İli ve Çevresi İklim Elemanlarının Dağılımı ve Meteorolojik Risk Haritaları. Devlet Meteoroloji İşleri Genel Müdürlüğü Yayınları, Antalya.

Çokuysal B, Erbaş E (2004) Bitkilerde Besin Maddeleri Noksanlıkları ve Toprak Tahlillerinin Değerlendirilmesi. EÜ Ziraat Fakültesi Toprak Bölümü Yayınları, Çiftçi broşürü No: 55, İzmir.

Davis PH (Ed.) (1972) Flora of Turkey and the East Aegean Islands. Edinburg Universty Press 4: 159-160.

Davis PH, Mill RR, Tan K (1972) Flora of Turkey and the East Aegean Islands book set. Edinburg University Press.

Ellison D (2002) An illustrated reference to garden plants of the world. New Holland Publisher, London.

Ganeva T, Uzunova K (2010) Comparative leaf epidermis study in species of genus Malus Mill. (Rosaceae). Botanica Serbica 34(1): 45-49.

Gültekin HC (2011) Eriolobus triobatus (Pair) Roeme. Orman ve Av Dergisi 2: 36-39.

Güner A, Aslan S, Ekim T, Vural M, Babaç T (edt.) (2012) Türkiye Bitkileri (Damarlı Bitkiler). Nezahat Gökyiğit Botanik Bahçesi ve Flora Araştırmaları Derneği yayını, İstanbul.

Korakis G, Poirazidis K, Papamattheakis N, Papageorgiou A (2006) New localities of the vulnerable species Eriolobus trilobatus (Rosaceae) in northeastern Greece, Plant, Fungal and Habitat Diversity İnvestigation and Conservation Proceedings of IV BBC: 422-426.

MingHao C, ZhiQin Z, HongPing D, XiaoLin L (2001) A study on the taxonomy of Malus trilobata Schneid, Chinese Society for Horticultural Science Acta Horticulturae Sinica 28(3): 268- 269.

Orman Genel Müdürlüğü (2014) Yabanil Meyveli Türler Eylem Planı 2014- 2018. https,//www.ogm.gov.tr/ ekutuphane /Yayinlar. Erişim 20 Mayis 2018.

Papamattheakis N, Papageorgiou AC, Poirazides K, Pipinis E, Doulis AD (2013) Conservation biology of the rare plant Eriolobus trilobatus in $\mathrm{NE}$ Greece. http,//www.agrobiodiversity.net/ greece/pdf/ General/. Erişim 28 Aralık 2018.

Petrova A (2015) Plants \& Fungi, Eriolobus triobatus. Red Data Book of the Republic of Bulgaria, Joint edition of the Bulgarian Academy of Sciences \& Ministry of Environment and Water, Vol 1, Sofya. http,/www.nationalredlist.org/red-data-book-of-the-republic-ofbulgaria-volume-1-plants-fungi. Erişim 28 Aralık 2018.

Polat R (2010) Havran ve Burhaniye (Balıkesir) Çevresinde Tarımsal Biyoçeşitlilik ve Etnobotanik Araştırmaları. Doktora Tezi, Balıkesir Üniversitesi Fen Bilimleri Enstitüsü, Balıkesir.

Ponomarenko VV (1989) Spontaneous interspecific and intergeneric hybridization in the genus Malus Mill. Nauchno- Tekhnicheskiı 
Byulleten' Vsesoyuznogo Ordena Lenina i Ordena Druzhby Narodov Nauchno-Issledovatel'skogo Instituta Rastenievodstva Imeni N. I. Vavilova 194: 53-58.

Robertson KR, Phipps JB, Rohrer JR, Smith PG (1991) A Synopsis of Genera in Maloideae (Rosaceae). Systematic Botany 16(2): 376394.

Robinson JP, Harris SA, Juniper BE (2001) Taxonomy of the Genus Malus Mill. (Rosaceae) With Emphasis on the Cultivated Apple, Malus Domestica Borkh. Plant Systematics and Evolution 226(1-2): 35-58.

Rohrer JR, Robertson KR, Phipps JB (1994) Floral Morphology of Maloideae (Rosaceae) and its Systematic Relevance. American Journal of Botany 81(5): 574-581.

Satıl F, Akçiçek E, Selvi S (2008) Madra Dağı (Balıkesir/ İzmir) ve Çevresinde Etnobotanik Bir Çalışma. Biyoloji Bilimleri Araştırma Dergisi 1(1): 31-36.

Sayılı M, Adıgüzel F, Gözener B (2010) Tokat İli Merkez İlçede Kuşburnu Ürünleri Tüketim Durumlar ve Tüketimde Etkili Faktörlerin Belirlenmesi. Tarım Ekonomisi Dergisi 16(2): 33-43.

Tuzlacı E (2002) Baba Dağı (Muğla) Florası ve Fethiye Yöresinde Halkın Yararlandığı Bitkiler Hakkında Bir Ön Araştırma. 14. Bitkisel İlaç Hammaddeleri Toplantısı, Eskişehir, s. 417-426.

Wood P (2015) The Street Tree, London's Street Tree, middle Eastern migrant adds sweet interest to London streets. https,//thestreettree.com/2015/09/20/middle-eastern-migrant-addssweet-interest-to-london-streets. Erişim 20 Ocak 2019.
Yilmaz M (2008) Optimum germination temperature, dormancy, and viability of stored, non- dormant seeds of Malus trilobata (Poir.) CK Schneid. Seed Science and Technology 36: 747-756.

Yılmaz M, Ok T (2012) Geyik Elması (Malus trilobata C.K Schneid.)'nın Bazı Biyolojik, Ekolojik ve Etnobotanik Özellikleri. Kahramanmaraş Sütçü İmam Üniversitesi Doğa Bilimleri Dergisi Özel Say1: 156-160.

Yılmaz M, Yüksel MC (2014) Mersin Yöresindeki Geyik Elması (Malus trilobata C. K. Schneid.) Gen Kaynakları. III. Uluslararası Odun Dışı Orman Ürünleri Sempozyumu, Kahramanmaraş, s. 116126.

Yılmaz M, Yüksel MC (2016) Geyik Elması (Malus trilobata C. K. Schneid.)'nın Etnobotanik Özellikleri ve Fidan Üretimi, El- Cezeri Journal of Science and Engineering 3(1): 1-8.

Yilmaz M, Parlak S, Kalkan M (2019) Güney Marmara ve Ege Bölgesindeki Geyik Elması (Malus trilobata C.K. Schneid.) Gen Kaynakları. Artvin Çoruh Üniversitesi Orman Fakültesi Dergisi 20(2): 1-6.

Zahreddine HG (2005) The Domestication of Lebanese Native Tree Species. Dissertation, Graduate School of The Ohio State University, Lebanon.

Zahreddine HG, Barker DJ, Quigley MF, Sleem K, Struve DK (2007) Patterns of woody plant species diversity in Lebanon as affected by climatic and soil properties. Lebanese Science Journal 8: 21-44. 